\title{
EL INTERÉS SUPERIOR DE LOS NIÑOS Y LAS NIÑAS, DE NUEVO SOBRE LA NECESIDAD DE LA CREACIÓN DEL CONCEPTO AUTÓNOMO DE SU RESIDENCIA HABITUAL. AUTO DE 24 DE OCTUBRE DE 2019 SECCIÓN DECIMOSEGUNDA DE LA AUDIENCIA PROVINCIAL DE BARCELONA*
}

\section{THE BEST INTEREST OF THE CHILDREN, ONCE MORE ABOUT THE NEED TO CREATE AN AUTONOMOUS CONCEPT OF THEIR HABITUAL RESIDENCE. ORDER OF OCTOBER 24, 2019 TWELFTH SECTION OF THE PROVINCIAL AUDIENCE OF BARCELONA}

\author{
LuCAs ANDrés PéRez MartíN** \\ Profesor Contratado Doctor de Derecho internacional privado \\ Universidad de Las Palmas de Gran Canaria \\ ORCID ID: 0000-0001-6340-0528
}

Recibido: 15.06.2020 / Aceptado: 03.07.2020

DOI: https://doi.org/10.20318/cdt.2020.5660

\begin{abstract}
Resumen: De nuevo apreciamos los negativos efectos de la falta de voluntad del legislador europeo y nacional de concretar un concepto autónomo de residencia habitual de los niños y las niñas, que permita concretar criterios de hecho para determinarla. Provoca que un procedimiento de medidas provisionales previas necesariamente urgente tarde diecinueve meses en iniciarse. Tal retraso perjudica claramente el interés de los niños y las niñas de acceso a una tutela judicial efectiva sin dilaciones indebidas. El auto de 24 de octubre de 2019 de la Sección decimosegunda de la Audiencia Provincial de Barcelona resuelve una inicial errónea valoración del Juzgado de Primera Instancia número 15 de Barcelona sobre la residencia habitual de un menor absolutamente evitable si la juzgadora hubiese contado con criterios legales claros para determinarla. La doctrina jurisprudencial existe, pero, aun así, tras la refundición de Bruselas II bis, quienes abogamos por la concreción normativa del concepto seguiremos esperado la necesaria reacción del legislador europeo.
\end{abstract}

Palabras clave: responsabilidad parental, residencia habitual de los niños y niñas, concepto autónomo, interés superior de los niños y niñas.

Abstract: Once more we appreciate the negative effects due to the lack of will of the European and National Legislator to specify an autonomous concept of habitual residence for boys and girls, which allows the definition of fact criteria to define it. This causes that a procedure of preliminary provisional measures,

"Este trabajo ha sido realizado en el marco del Proyecto de Investigación I+D+I: "Obstáculos a la movilidad de personas en los nuevos escenarios de la UE", financiado por el Ministerio de Economía y Competitividad, Dirección General de Investigación Científica y Técnica, con la referencia DER2017-86017-R.

**1ucas.perez@ulpgc.es 
which are necessarily urgent, takes nineteens months to start. Such delay clearly damages the interest of boys and girls to access to an effective judicial protection without undue delay. The ruling of October 24, 2019 of the twelfth section of the Provincial Court of Barcelona resolves an initial erroneous assessment from the Court of First Instance number 15 of Barcelona, which includes that the habitual residence of a minor would be absolutely avoidable, if the judge had clear legal criteria to determine it. The jurisprudential doctrine exists, but even so, after the amendment of Brussels II bis, those of us who advocate the regulation concretion of the concept will continue to await the necessary reaction from the European Legislator.

Keywords: Parental responsibility, habitual residence of children, Autonomous concept, best interests of the child.

Sumario: I. Los hechos, de la oscuridad a la claridad. II. ¿El interés del menor? Procedimiento sumario y falta de definición del requisito previo. 1. Procedimiento sumario, responsabilidad parental y aplicación de Bruselas II bis. 2. Refundición de Bruselas II bis, interés del menor e indefinición de la residencia habitual. III. Los criterios, ¿aparente dificultad? 1. La presencia física, el lugar de la vida del menor, criterio inicial, no suficiente. 2. Motivos, circunstancias y voluntad de los padres en el cambio de residencia. IV. A vueltas con la creación de un concepto autónomo. 1. Por un concepto autónomo de residencia habitual. 2. Criterios de la residencia habitual de los niños y niñas. V. Conclusiones.

\section{Los hechos, de la oscuridad a la claridad}

1. Surge ante nosotros una nueva oportunidad para defender la necesidad de que el legislador europeo debe aportar un concepto autónomo de la residencia habitual de las personas en general y de los niños y las niñas en particular, así como la concreción de unos claros criterios fácticos para establecerla, aportando seguridad jurídica y con ello defendiendo el interés más necesario de protección ${ }^{1}$. La historia se repite. Los hechos parecen confusos, pero si los analizamos con detenimiento nos llevan de la aparente oscuridad inicial a una gran claridad. Procedimiento sumario de medidas provisionales de un matrimonio en crisis con residencia de los padres en distintos lugares. Proceso que requiere resolución inmediata. Menor de corta edad con un cambio de residencia consensuada de sus padres previa al conflicto y la vuelta de uno de ellos al lugar de residencia anterior. Necesidad de resolución veloz para determinar las medidas de la responsabilidad parental y procedimiento que tarda diecinueve meses, casi dos años, siquiera en empezarse por una errónea valoración de la residencia habitual del hijo de los cónyuges. Todo evitable si la Juzgadora de Instancia hubiese tenido unos criterios legales claros, los conociese y los aplicase.

2. El Auto de la Sección decimosegunda de la Audiencia Provincial de Barcelona de 24 de octubre de $2019^{2}$ resuelve el recurso interpuesto por la madre del menor ante la declaración de incompetencia judicial internacional de los Tribunales españoles del Auto del Juzgado de Primera Instancia ${ }^{\circ} 15$ de

\footnotetext{
${ }^{1}$ En el caso de los niños y las niñas ese interés se plasma, entre otros aspectos, en la necesidad de acceder a la tutela judicial efectiva sin demoras indebidas. Este ha sido un concepto muy estudiado por la doctrina en el que no podemos detenernos, pero que dejamos citado. Un reciente estudio general, transversal desde la perspectiva del Derecho civil tan relacionado con este supuesto es el de L. VÁzquez-PASTor JimÉNEZ, "El interés superior del menor de edad en situación de desprotección como principio rector dela actuación de los poderes públicos”, $B M J$, año LXXIII, julio 2019, núm. 2.221, pp. 1 a 89. O también, M. P. García Rubio, “Aproximación al significado, contenido y alcance del interés del menor”, en Varios, Relaciones transfronterizas, globalización y derecho, homenaje al profesor Dr. José Carlos, Fernández Rozas, Pamplona, Aranzadi, 2020, pp. 1175 a 1090. Respecto al interés superior del menor en el Convenio de la Haya de 1980 sobre aspectos civiles de la sustracción internacional de menores, vid. E. Pérez Vera, Informe explicativo del Convenio de La Haya de 25 de octubre de 1980 sobre aspectos civiles de la sustracción internacional de menores, esp. párrafo núm. 114, disponible en https://www.hcch.net/es/ publications-and-studies/details4/?pid=2779. Consultado el 12 de junio de 2020. Sobre la importancia práctica del principio del interés general del menor en nuestra disciplina internacional privatista y los efectos que puede provocar, vid. A. MERCHAN MuriLlo, "El interés superior del menor como cuestión de fondo", $C D T$, marzo 2020, Vol. 12, № 1, pp. 635-644.

${ }^{2}$ Auto de la AP Barcelona de 24 octubre 2020, ECLI:ES:APB:2019:8448A.
} 
Barcelona de 15 de diciembre de $2018^{3}$, confirmando que los Tribunales españoles sí son competentes para conocer del procedimiento. En esencia los hechos nacen en Ginebra, al igual que el hijo en 2016, fruto de la pareja de nacionalidad española casada en la ciudad suiza en fecha que desconocemos. Los tres miembros de la familia se trasladan a Barcelona y se empadronan en ella el 27 de mayo de 2017. Alega el padre que de manera temporal y que la residencia "oficial" de la familia seguía siendo Ginebra, y la madre niega el acuerdo de dicha temporalidad. El trabajo del padre le exige a viajar por distintos países sin obligarle a permanecer en Suiza. El 17 de marzo de 2017 celebraron contrato de arrendamiento de vivienda en Barcelona por un periodo inicial de 3 años. El hijo, de un año de edad en dicho momento, es inscrito y acude a una guardería en la misma ciudad durante el curso 2017/2018. A principios de 2018 surge el conflicto familiar. El padre quiere volver a Ginebra y la madre permanecer en Barcelona. El padre comunica a la guardería que el 28 de febrero de 2018 volverán a Ginebra, y al arrendador que resolverán el contrato. La madre inicia el procedimiento de medidas provisionales previas en Barcelona el 13 de marzo de 2018. Diecinueve meses después la Audiencia Provincial de Barcelona resuelve que la residencia del menor es España y revoca el auto de instancia, devolviendo los autos al Juzgado de Primera Instancia para que siga con el procedimiento ${ }^{4}$

\section{II. ¿El interés del menor? Procedimiento sumario y falta de definición del requisito previo}

\section{Procedimiento sumario, responsabilidad parental y aplicación de Bruselas II bis}

3. Desde la perspectiva procesal civil estamos ante un procedimiento de medias provisionales previas que requiere de una tramitación sumaria regulado en el 771 de la LEC iniciado por uno de los cónyuges cuando ya vivían en distintos Estados o la separación de facto era inminente, para determinar las medidas establecidas en los artículos 102 y 103 del $\mathrm{CC}^{5}$, relativas tanto a la relación conyugal como a la paterno filial ${ }^{6}$. Antes de entrar en el análisis de la residencia habitual del menor, que es el objeto de nuestro estudio, es obligado hacer una precisión previa. El procedimiento iniciado solicita medidas que abarcan tanto las relaciones conyugales como respecto al menor, con un elemento de internacionalidad. Ambos tribunales vincularon el estudio de su competencia únicamente a la residencia del menor, atrayendo el ejercicio de la responsabilidad parental ${ }^{7}$ al propio procedimiento de divorcio. El Reglamento Bruselas II

\footnotetext{
${ }^{3}$ Dictado en los Autos de medidas provisionales previas (art. 771 LEC) 164/2018. Sin publicación oficial en los repertorios habituales agradecemos al Letrado de la Administración de Justicia del Juzgado, Don Oscar Aldaz Alfranca la disponibilidad del envío del mismo tan pronto finalizó la paralización de actuaciones judiciales por la declaración del Estado de Alarma según la Disposición Adicional Segunda del Real Decreto 463/2020, de 14 de marzo, por el que se declara el estado de alarma para la gestión de la situación de crisis sanitaria ocasionada por la Covid-19 (BOE núm. 67, de 14 de marzo de 2020).

${ }^{4}$ Hechos derivados de la lectura de los dos Autos. Podría haber algún detalle concreto que hubiésemos querido confirmar en los escritos de las partes a los que no hemos podido tener acceso, pero que se pueden derivar del FJ segundo del Auto de apelación. En aras de la claridad del análisis del Auto queremos señalar los datos que expresamente se recogen y los que inferimos. El Auto señala con claridad las fechas de traslado de las partes y la nacionalidad del padre. No recoge de forma expresa la nacionalidad de la madre, pero afirma aplicable no el periodo de 1 año del artículo 3 del Reglamento Bruselas II bis, sino los 6 meses derivados de la nacionalidad del demandante del lugar de su residencia habitual (siendo esta Barcelona), de lo que derivamos la nacionalidad española de la madre. Por otro lado, señala los tres años del arrendamiento de forma expresa.

${ }_{5}^{5}$ Para consultar los aspectos generales de las medidas de los artículos 102 y 103 del CC, desde la perspectiva civil, vid. C. Lasarte Álvarez, Principios de Derecho Civil. Derecho de Familia, Tomo 6, Marcial Pons, Madrid, novena edición, 2010, pp. 120 a 124.

${ }^{6}$ Para conocer los aspectos generales del procedimiento del artículo 771 de la LEC, desde la perspectiva procesal, vid. H. Soleto Muñoz, Las medidas provisionales en los procesos de familia, Tirant Lo Blanch, Valencia, 2020, pp. 107 a 147.

${ }^{7}$ La responsabilidad parental, en palabras del TJUE, se concreta en "los derechos y obligaciones conferidos a una persona física o jurídica en virtud de una resolución judicial, por ministerio de la ley o por un acuerdo con efectos jurídicos, en relación con la persona o los bienes de un menor". Vid. STJUE de 27 de noviembre de 2007, Caso C, Asunto C-435/06, ECLI:EU:C:2007:714, párrafo 53. Artículo 2 de Bruselas II bis y su refundición. Al respecto de la complejidad del concepto y las medidas que abarca, vid. A. Durán Ayago, "Responsabilidad parental, relaciones paterno-filiales y protección de menores: ¿tres denominaciones para tres realidades diferentes?”, en M. GuZmán ZaPATER y C. Esplugues Mota (directores), Persona y familia en el nuevo modelo español de Derecho internacional privado, Valencia, Tirant lo Blanch, 2017, pp. 353 a 363 , p. 360.
} 
bis $^{8}$, aplicable en dicho supuesto ${ }^{9}$, diferencia los criterios de conexión de la competencia respecto a ambos tipos de acciones. Por un lado, los criterios del procedimiento de divorcio (y por lo tanto las medidas vinculadas al divorcio) son reguladas en el artículo 3 con diversos foros alternativos, mientras que el criterio para establecer la competencia respecto a la responsabilidad parental se regula en el artículo 8 con un solo criterio, la residencia habitual del menor. Por ello, la competencia para ambas acciones puede ser del mismo Estado o no, con la posibilidad del juego de la competencia conjunta entre ambas acciones con diferente residencia del menor del lugar competente para el divorcio por el foro de accesoriedad si se dan las condiciones del artículo $12^{10}$. Sin entrar en dicho aspecto, ciertamente con contenido propio ${ }^{11}$, en el presente trabajo nos centraremos en la competencia vinculada a la responsabilidad parental.

4. El Tribunal de Instancia aplica incorrectamente el artículo 22 de la LOPJ ${ }^{12}$. En un procedimiento de divorcio con elemento de internacionalidad en el que los Tribunales españoles conocen si son competentes o no, ya hemos señalado que el Derecho aplicable es el Reglamento Bruselas II bis, teniendo la aplicación del artículo 22 de la LOPJ un ámbito de aplicación residual ${ }^{13}$. En todo caso el precepto nos remite al mismo criterio de localización de la competencia judicial del Reglamento europeo, la residencia habitual del menor ${ }^{14}$. La Audiencia Provincial aplica el régimen legal correcto, Bruselas II bis, que recoge en su considerando decimosegundo que el interés superior del menor radica en vincular el procedimiento con el lugar en el que reside en el momento de la crisis familiar a través del criterio de conexión de la competencia ${ }^{15}$.

\section{Refundición de Bruselas II bis, interés del menor e indefinición de la residencia habitual}

5. En los trabajos legislativos para la aprobación del Reglamento $1111 / 2019^{16}$, el interés superior del menor motivó las tomas de posición en los informes de la Comisión Europea ${ }^{17}$, del Parlamento Euro-

\footnotetext{
${ }^{8}$ Reglamento de la Unión Europea 2201/2003, de 27 de noviembre de 2003, relativo a la competencia, el reconocimiento y la ejecución de resoluciones judiciales en materia matrimonial y de responsabilidad parental, que deroga el Reglamento CE n 1347/2000, conocido como Bruselas II bis (DO L núm. 338, de 23 de diciembre de 2003).

9 Vid. A. Rodríguez Benot (director), Derecho internacional privado, Madrid, Tecnos, quinta edición, 2018, pp. 71 a 73.

${ }^{10}$ Sobre el principio de accesoriedad para la unión o separación de estos procedimientos, vid. J. C. FernÁndez RozAS y S. SÁnchez Lorenzo, Derecho internacional privado, Pamplona, Aranzadi, décima edición, 2018, pp. 401 a 403.

${ }^{11}$ Sobre la dificultad que también supondría la residencia habitual del menor fuera de la UE con competencia para el divorcio en un Estado miembro de la UE y su relación con el interés superior del menor, vid. I. Lorente Martínez, "Divorcio en España y menores con residencia habitual fuera de la Unión Europea”, en A. Cebrián SAlvat e I. Lorente Martínez, Protección de menores y Derecho Internacional Privado, Granada, Comares, 2018, pp. 104 y 105.

${ }_{12}$ Por desgracia no es hecho excepcional. Al respecto, vid. A. QuiÑonEs EscÁmez, “¿Cuándo se aplica el Reglamento Bruselas II bis? El TJCE se pronuncia sobre su ámbito de aplicación”, RDCE, no 29, mayo y agosto 2008, pp. 457 a 482 , p. 465, o I. OtAegui Aizpurua, "La errónea determinación de la competencia judicial internacional cuando los hijos residen en Estados miembros diferentes: Sentencia de la AP de Lugo no 44/2018, de 11 de abril de 2018”, CDT, marzo 2019, Vol. 11, No 1, pp. 870-876.

${ }_{13} \mathrm{Al}$ respecto, vid. A. Calvo Caravaca y J. Carrascosa González, Derecho internacional privado, Granada, Comares, decimoctava edición, 2018, Vol. II, p. 248, y M. GuZmán PeCes, "La competencia judicial en materia de nulidad, separación y divorcio; responsabilidad parental y sustracción civil de menores en el Derecho internacional privado español”, en M. GuZMÁN Zapater y M. Herranz Ballesteros (directoras), Crisis matrimoniales internacionales y sus efectos. Derecho español y de la Unión Europea, Valencia, Tirant lo Blanch, 2018, pp. 257 a 261, p. 250.

${ }^{14}$ Vid. F. J. Garcimartín Alférez, Derecho internacional privado, Cizur Menor, Aranzadi, quinta edición, 2019, p. 152.

$15 \mathrm{Vid}$. Considerando 12: "Las normas de competencia que establece el presente Reglamento en materia de responsabilidad parental están concebidas en función del interés superior del menor, y en particular en función del criterio de proximidad. Esto significa por lo tanto que son los órganos jurisdiccionales del Estado miembro en el cual el menor tiene su residencia habitual los que deben ser competentes en primer lugar". Al respecto, y en relación al derecho italiano y francés y la residencia habitual en el Reglamento Bruselas II bis, vid. G. CAmpiglio, "Il foro della residenza abituale del coniuge nel regolamento (CE) n 2201/2003: note a margine delle prime pronuncie italiane", CDT, octubre 2010, Vol. 2, No 2, pp. 242 a 249, pp. 247 a 249.

${ }^{16}$ Reglamento (UE) 2019/1111 del Consejo, de 25 de junio de 2019, relativo a la competencia, el reconocimiento y la ejecución de resoluciones en materia matrimonial y de responsabilidad parental, y sobre la sustracción internacional de menores (versión refundida), DOUE L178/1 de 2 de julio de 2019.

17 Vid. COMISIÓN EUROPEA, Propuesta de REGLAMENTO DEL CONSEJO relativo a la competencia, el reconocimien-
} 
peo $^{18} \mathrm{y}$ del resto de Instituciones que intervinientes ${ }^{19}$. Bajo esa premisa, nunca se cuestiona que el Estado competente para conocer de los asuntos relacionado con los menores es el de su residencia habitual. En todos los aspectos que el legislador europeo quiso mejorar el contenido del reglamento para la mayor protección del menor el eje central es el mantenimiento del lugar en el que el menor tiene su día a día como el que debe asumir la competencia del proceso. En la sustracción internacional, la mejora de proceso de restitución y el refuerzo del sistema de retorno con el mecanismo de última palabra, en el refuerzo del derecho del menor a ser oído, o en la posibilidad de decisión conjunta de los padres para elegir el lugar de la residencia anterior como competente. En todos los supuestos el Estado en el que se encuentra la residencia habitual del niño o la niña -en la refundición según el artículo 7- asume la competencia ${ }^{20}$.

6. Sin embargo, el legislador europeo no ha creído necesario definir la residencia habitual. No hay ni una referencia en todos los trabajos legislativos anteriormente citados que ni siquiera cite la conveniencia o no de definir este concepto nuclear en el texto del Reglamento, sea en sus considerandos o en su articulado. Y de hecho el Reglamento modifica las definiciones reestructurando y actualizando las de juez y documento público, y añadiendo en el artículo 2.6 una absolutamente novedosa, la de niño, como persona menor de 18 años. Podemos afirmar que es una posición del legislador europeo la falta de conveniencia de aportar una definición de residencia habitual ${ }^{21}$, aunque no podamos conocer su motivación para ello, ya que en ningún documento está expuesta ${ }^{22}$. Por todo lo cual, quienes defendemos la conveniencia de dicha definición ${ }^{23}$ debemos seguir esperando a que el legislador europeo vuelva a la senda abierta por primera y única vez en el Reglamento de Sucesiones estableciendo criterios, en los considerandos 23 y $24^{24}$.

\section{Los criterios, ¿aparente dificultad?}

7. Entremos en el análisis práctico del caso. El Juzgado de primera instancia considera que España no es competente porque el menor tiene la residencia habitual en Ginebra, con tres argumentos. Nació en Ginebra, los progenitores tenían su domicilio permanente en dicha ciudad ${ }^{25}$, y por último, un

to y la ejecución de resoluciones en materia matrimonial y de responsabilidad parental, y sobre la sustracción internacional de menores (refundición), COM/2016/0411 final - 2016/0190 (CNS), motivación y objeto de la propuesta, p. 2. Antes de llegar al propio texto el concepto interés superior del niño es nombrado 14 veces.

${ }_{18} \mathrm{Vid}$. PARLAMENTO EUROPEO, Informe sobre la propuesta de Reglamento del Consejo relativo a la competencia, el reconocimiento y la ejecución de resoluciones en materia matrimonial y de responsabilidad parental, y sobre la sustracción internacional de menores (refundición), COM(2016)0411 - C8-0322/2016 - 2016/0190(CNS), nombrado 28 veces. También, vid. Resolución del PARLAMENTO EUROPEO de 28 de abril de 2016, sobre la protección del interés superior del menor en toda la Unión sobre la base de las peticiones dirigidas al Parlamento Europeo 2016/2575(RSP), (2018/C 066/01).

19 Vid. Dictamen del Comité Económico y Social Europeo sobre la «Propuesta de Reglamento del Consejo relativo a la competencia, el reconocimiento y la ejecución de resoluciones en materia matrimonial y de responsabilidad parental, y sobre la sustracción internacional de menores (refundición)» [COM (2016) 411 final - 2016/019 (CNS)], (2017/C 125/06).

${ }^{20}$ Para analizar los trabajos de la refundición en el momento en el que se desarrollaban, vid. E. Rodríguez PINEAU, "La refundición del Reglamento Bruselas II bis: de nuevo sobre la función del Derecho internacional privado europeo", REDI, vol. 69/1, enero - junio 2017, pp. 139 a 165.

${ }_{21}$ Sobre las dificultades que esta falta de definición provoca, vid. B. CAmpuzano Díaz, "El nuevo Reglamento (UE) 2019/1111: análisis de las mejoras en las relaciones con el Convenio de la Haya de 19 de octubre de 1996 sobre responsabilidad parental" CDT, marzo 2020, vol. 12, nº 1, pp. 97 - 117, pp. 109 a 111

${ }^{22}$ En 62 ocasiones se nombra la residencia habitual en la propuesta de la Comisión, 56 en el texto de las modificaciones y 6 en la exposición de motivos, y en ninguna de ellas se cita la conveniencia o no de aportar una definición. Podemos apreciar una propuesta de los motivos de ese silencio en el Reglamento Europeo de Sucesiones en; J. CARRASCOSA GonzÁLEz, "El concepto de residencia habitual del causante en el Reglamento sucesorio europeo", BARATARIA, Revista Castellano-Manchega de Ciencias Sociales, № 19, 2015, pp. 15-35, p. 19

${ }^{23}$ Misma opinión se puede observar, por ejemplo, en M. A. Gandía Sellens, "La responsabilidad parental y la sustracción de menores en la propuesta de la Comisión para modificar el RB II Bis: algunos avances, retrocesos y ausencias", AEDIPr, T. XVII, 2017, pp. 799 a 820, p. 814.

${ }^{24} \mathrm{Vid}$. I. Rodríguez-Uría SuÁrez, "La ley aplicable a las sucesiones mortis causa en el Reglamento (UE) 650/2012", InDret, abril 2013, pp. 1 a 58, p. 15.

${ }^{25}$ FJ único del Auto de Instancia. La Juzgadora emplea el término en pasado, “tenían”. 
cambio unilateral de la residencia de la madre a Barcelona no puede considerarse que provoque la modifica la residencia habitual del menor. El Auto de la Audiencia Provincial considera que la residencia habitual es España porque el menor se encuentra aquí viviendo en el momento del inicio de la crisis familiar, está escolarizado en Barcelona sin que haya una obligación legal para ello, el contrato de alquiler de la vivienda en la que reside se suscribió para tres años y porque la decisión inicial del traslado de Suiza a España fue conjunta de ambos padres ${ }^{26}$. A falta de la definición legal de residencia habitual, recurriremos al concepto autónomo creado por la Jurisprudencia del TJUE para valorar el acierto de la Segunda Instancia.

\section{1. la presencia física, el lugar de la vida del menor, criterio inicial, no suficiente}

8. En la comparación entre el criterio del nacimiento en Suiza que aplica la Juzgadora de Instancia y el de la efectiva presencia del menor en España que aplica la Audiencia, es absolutamente claro que la Jurisprudencia del TJUE da preferencia al de la presencia física. Por ejemplo, en la Sentencia de 17 de octubre de $2018, U D^{27}$, en un supuesto en el que determinaba la residencia habitual de una menor que nunca había vivido en la $\mathrm{UE}^{28}$, señala claramente que la presencia física de los niños y las niñas es un requisito absolutamente imprescindible para determinar su residencia habitual en un Estado miembro de la UE, y por su falta de vida previa en la UE la menor no tenía su residencia en ella, independientemente las causas vinculadas a dicha vida en un tercer Estado ${ }^{29}$. Es un caso asimilable por cierta analogía a este supuesto en el que el Juzgado de Instancia prefirió en diciembre de 2018 el criterio del nacimiento del hijo en Ginebra en 2016 a su residencia en España desde mayo de 2017 a marzo de 2018, fecha en la que se inicia el proceso ${ }^{30}$.

9. También es aplicable a este supuesto la doctrina de la STJUE de 28 de junio de $2018, H R^{31}$, en la que en un supuesto en el que una mejor tenía relación de forma simultánea con dos países a la vez, Polonia y Bélgica ${ }^{32}$, afirma con rotundidad que las circunstancias de hecho de la nacionalidad, origen y otras raíces de la menor, como las lingüísticas, decaen frente a la presencia física en un determinado

${ }^{26}$ FJ Segundo del Auto de la Audiencia Provincial de Barcelona de 24 de octubre de 2019 en el que se cita la STJUE de 13 de octubre de 2016, aunque consideramos que hay resoluciones más cercanas al caso que analizamos en nuestro trabajo. También opinaba que la residencia del menor es España el Juzgado de Primera Instancia $n^{\circ} 13$ de Ginebra, que paralizó, con dicha opinión y pendiente de la resolución de los Tribunales españoles, el proceso iniciado por el padre en Suiza sobre responsabilidades parentales y otras medidas provisionales.

${ }^{27}$ Asunto C-393/18, ECLI:EU:C:2018:835.

${ }^{28}$ La demandante (UD), bangladesí, y el demandado (XB), británico, se habían conocido en el Reino Unido y casado en Bangladés en 2013. Tras tener una primera hija y residir brevemente en el Reino Unido se trasladan en diciembre de 2016 a Bangladés con la finalidad de que la madre dé a luz en su país natal. La menor nace el 2 de febrero de 2017. La madre se queda residiendo con ella en Bangladés mientras que el padre vuelve al Reino Unido en enero de 2018. La demandante alegó que no podía volver al Reino Unido por coacciones ejercidas por su familia y violencia de género ejercida por el padre, y que la segunda hija tenía residencia habitual en el Reino Unido a pesar de no haber vivido nunca allí.

${ }^{29}$ Estudia esta Sentencia con mucho acierto B. CAmpuzano Díaz, "Una nueva sentencia del TJUE sobre el concepto de residencia habitual en el macro del Reglamento 2201/03: sentencia de 17 de octubre de 2018, UB y XB, AS. 393/18 PPU”, CDT, octubre 2019, Vol. 11, n² 2, pp. 462 a 471. También la analizamos en L. A. Pérez Martín, "Residencia habitual de los menores y vulneración de derechos fundamentales (STJUE de 17 de octubre de 2018, asunto C-393/18, PPU)", La Ley Unión Europea, $\mathrm{N}^{\circ} 66$, año VII, enero de 2019, pp. 107 a 120.

${ }^{30}$ El momento que debe ser valorado es marzo de 2018, fecha en que se presenta el asunto ante el órgano judicial -artículo 8 Bruselas II bis-.

${ }^{31}$ Asunto C-512/17, ECLI:EU:C:2018:513.

${ }^{32}$ En el supuesto la menor nace en Bélgica en 2015, hija de una funcionaria polaca del SEAE de la UE (HR) y un ciudadano belga (KO). La niña desarrolla su vida habitual en Bruselas, donde vive con sus padres, sin asistir a la guardería, y ha disfrutado de largas estancias en Polonia en el marco de sus vacaciones y periodos festivos junto a su familia materna, algunas de ellas durando hasta tres meses. Los padres finalizan su convivencia en agosto de 2016 y llegan a un acuerdo verbal sobre la menor, que reside con la madre en Bélgica, visitándola su padre una vez por semana. La madre afirmaba que la menor, empadronada en ambos Estados, tiene residencia habitual en Polonia, y el padre, que la tiene en Bélgica. El TJUE la estableció en Bélgica, lugar de presencia física habitual de la menor 
Estado $^{33}$. En este supuesto, con relación del menor con Suiza y España, la relación física con Ginebra fue en el momento de su nacimiento y su primer año, y el año anterior a la interposición de la demanda la relación la mantuvo de forma continuada únicamente con España, empadronado y viviendo con sus padres en una vivienda alquilada por tres años en Barcelona desde mayo de 2017 a marzo de 2018 y acudiendo aquí a la guardería. Aquí se encontraba su "centro habitual de vida e intereses" ${ }^{34}$.

\section{Motivos, circunstancias y voluntad de los padres en el cambio de residencia}

10. El lugar en el que se materializa la vida e intereses de los niños y niñas depende, según la Jurisprudencia ya consolidada del TJUE, de varios hechos. Desde la sentencia de 2 de abril de 2009 , caso $A^{35}$, seguida por varias otras resoluciones ${ }^{36}$, los hechos a valorar son los de la duración, regularidad, condiciones y razones de la permanencia en el territorio de un Estado miembro y del traslado de la familia a dicho Estado. También la nacionalidad del menor, el lugar y las condiciones de escolarización, sus conocimientos lingüísticos y las relaciones familiares y sociales que el menor mantiene en el referido Estado. En este supuesto, el traslado y la residencia en España tenían cierta estabilidad. Lo demuestran los 3 años del alquiler, que se inscribiese al menor en una guardería, aunque no hubiese obligación legal de ello, o que la vuelta a Ginebra la decidiese el padre únicamente cuando surge la crisis familiar.

11. Un aspecto al que le da importancia la resolución de instancia es la unilateralidad del cambio de domicilio de la madre, que no puede suponer el cambio de residencia habitual del menor. Aclaremos antes que la Audiencia Provincial (y nosotros con ella) discrepa de esta valoración. De los hechos descritos se desprende un traslado voluntario de ambos cónyuges ${ }^{37}$, ya que la familia se traslada unida a Barcelona, se empadronan, firman un contrato de alquiler por 3 años e inscriben los niños en la guardería. Es solo la crisis la que provoca la intención del padre de volver a Ginebra. Pues bien, incluso aunque el acuerdo hubiese sido el de venir a España de forma provisional y la madre se hubiese arrepentido de dicha decisión, la Jurisprudencia del TJUE ha resuelto ya no valorar dicho cambio de posición y establecer la residencia habitual en el lugar en el que se encontraba el menor en el momento del inicio del procedimiento, siendo los acuerdos previos entre los padres indiferentes. Esta doctrina la encontramos en la Sentencia de 8 de junio de 2017, asunto $O L^{38}$, en la que el TJUE establece que se debe valorar muy determinantemente que la menor no fue trasladada a un tercer Estado por uno de los padres sin el consentimiento del otro. En tal situación no se puede alegar que el interés de la menor fuese volver a su residencia anterior, sin que los acuerdos entre los padres tengan valor para establecer la residencia de la menor, debiendo valorarse por encima de ellos su integración en el lugar en el que vive, con el que tiene

${ }^{33}$ Criterio de proximidad esencial para determinar la Competencia Judicial. Sobre la trascendencia de la presencia física del menor en el momento del inicio del proceso y el cambio de Estado competente por el traslado de la residencia habitual, vid. S. Álvarez GonzÁlez, "Competencia judicial internacional para la modificación de sentencia en materia de responsabilidad parental y de obligaciones alimenticias. STJUE de 15 de febrero de 2017, asunto C-499/15: W y V", La Ley Unión Europea, № 47 , abril de 2017 , pp. 1 y ss.

34 Apartado 22 de la ya clásica Sentencia de 15 de septiembre de 1994, caso Magdalena, Asunto C-452/93, ECLI:EU:C:1994:332, que recogió la primera y genérica inicial definición del concepto de residencia habitual del TJUE.

${ }^{35}$ Asunto C-523/07, ECLI:EU:C:2009:225. El 23 de febrero de 2005, los servicios sociales del municipio de L (Suecia) asumieron la guarda inmediata de los menores A y B nacidos en 1999 y 2001, de nacionalidad finlandesa. El 1 de marzo de 2005 la madre se traslada a Finlandia. Cuando se fue a ejecutar la resolución sueca en Finlandia la madre se negó. Finalmente, el TJUE estimó que la residencia habitual era la de Suecia.

${ }^{36}$ Como la Sentencia de 22 de diciembre de 2010, caso Mercredi, por ejemplo. Asunto C-497/10, ECLI:EU:C:2010:829.

${ }^{37}$ Un detallado estudio de situaciones complejas, alguna de ellas similares a las del caso lo podemos apreciar en J. CARRAScosa GonZÁlez, "Reglamento sucesorio europeo y residencia habitual del causante", CDT, marzo 2016, Vol. 8, n¹, pp. 47-75, en concreto y señalando supuestos complejos, en pp. 65 a 74.

${ }^{38}$ Asunto C-512/17, ECLI:EU:C:2017:436. OL, italiano, y PQ, griega, contrajeron matrimonio el 1 de diciembre de 2013, residiendo inicialmente en Italia. En el octavo mes de embarazo, ambos deciden que la madre daría luz en Atenas, y la niña nace el 3 de febrero de 2016. El padre se desplaza a Italia y acuerdan que en mayo la madre y la niña volverán al citado país. En junio la madre decide unilateralmente permanecer en Grecia afirmando que nunca concretaron la fecha de su vuelta a Italia. En julio de 2016 el padre inicia procedimientos en Italia y Grecia. El TJUE concreta la residencia habitual de la menor en Grecia. 
un vínculo físico. Si se hubiese aplicado esta doctrina a nuestro supuesto nunca se habría considerado que la residencia era España ${ }^{39}$.

\section{A vueltas con la concreción de un concepto autónomo}

\section{Por un concepto autónomo de residencia habitual}

12. Finalizamos deteniéndonos en los argumentos de nuestra opinión sobre la necesidad de la elaboración legislativa de un concepto de residencia habitual que otorgue seguridad a los distintos operadores jurídicos y que pueda ayudar a evitar estas dilaciones indebidas que vulneran los derechos de los niños y las niñas ${ }^{40}$. Existen instituciones jurídicas en las que este concepto puede no ser oportuno, pero en las instituciones de naturaleza fáctica de gran trascendencia práctica y un evidente perfil europeo diferenciado de los perfiles nacionales, los conceptos autónomos son especialmente eficaces y necesarios. Uno de ellos es la residencia habitual ${ }^{41}$, y en concreto en lo relativo a los niños y las niñas en el Reglamento Bruselas II bis ${ }^{42}$. Su componente fáctico provoca que sea un concepto difícil de con$\operatorname{cretar}^{43}$, pero creemos que es factible, sin concretarla en un determinado periodo de tiempo ${ }^{44}$, sino en las circunstancias, motivaciones y características de la residencia.

13. Esta elaboración de la definición respondería, sí, a la defensa del interés superior del menor toda vez que facilitaría su acceso a una tutela judicial efectiva sin retrasos indebidos ${ }^{45}$ evitando evidentes graves problemas a los niños y niñas, tales como los ocasionados en el supuesto analizado, iniciado casi con dos años de retraso ${ }^{46}$. Esta definición no debe ser una definición cerrada, cuantitativa, pero sí debe ser indicativa de las circunstancias y características de hecho que debe tener la estancia de un niño o niña en un Estado miembro para considerar que en él tiene su residencia habitual ${ }^{47}$.

39 Vid. M. C. ChéLIz Inglés, La sustracción internacional de menores y la mediación. Retos y vías prácticas de solución, Tirant lo Blanch, Valencia, 2019, págs. 46 y ss. para conocer las distintas posturas jurisprudenciales que se han producido en los distintos Estados para establecer mayor o menor valor a las posiciones de los padres. También repertorio especialmente práctico de resoluciones en P. MCLEAVY, INDACAT, en https://www.incadat.com/es/convention/case-law-analysis. Consultada el 12 de junio de 2020.

${ }^{40}$ Con más detalle en L. A. Pérez Martín, "Propuesta de un concepto europeo de residencia habitual en derecho de familia internacional”, AEDIPR, T. XVIII, 2018, pp. 469 a 494, pp. 487 a 491.

${ }^{41}$ Así lo opina expresamente S. A. SÁnchez Lorenzo, en "El principio de coherencia en el Derecho internacional privado europeo", REDI, Vol. 70, 2018 n 2, p. 30.

${ }^{42}$ Opina que este es un concepto autónomo J. CARRASCOSA GonZÁlez en "Litigación internacional, responsabilidad parental y foro de la residencia habitual del menor en un estado miembro. Un estudio jurisprudencial”, en A. Cebrí́n SALVAT e I. LorENTE Martínez, Protección de menores y Derecho Internacional Privado, Granada, Comares, 2018, pp. 305 a 323, p. 315, sin que se pronuncie sobre si esa falta de definición es un defecto del Reglamento o no, atendiendo a su naturaleza fáctica.

${ }^{43}$ Lo destaca P. ORejudo Prieto de los Mozos en "Diez años de aplicación e interpretación del Reglamento Bruselas II bis sobre crisis matrimoniales y responsabilidad parental (análisis de los aspectos de competencia judicial internacional)", La Ley Unión Europea, № 21, año II, mayo de 2014, pp. 5 a 22, p. 17.

${ }^{44}$ Al respecto, vid. E. CLIVE, "The concept of Habitual Residence”, Juridical Review, 1997, pp. 137 a 143, si bien reconoce que en el caso de los matrimonios se puede entender que la Jurisprudencia establecía un año como el tiempo para determinar la residencia habitual de la pareja (p. 137), en el caso de los niños y niñas dicha concreción no es posible (p. 142).

${ }^{45}$ De la misma opinión es R. Lamont, "Habitual Residence and Brussels IIbis: Developing Concepts for European Private International Family Law", Journal of Private International Law, octubre 2007, Vol. 3 No. 2, pp. 261-281, p. 274. También Zhang afirma que es un defecto de los tratados internacionales que analiza la falta de definición del concepto toda vez que esta falta de definición provocará una gran dificultad para determinar la residencia habitual en los casos conflicticos. Vid. M. ZHANG, "Habitual Residence v. Domicile: A Challenge Facing American Conflicts of Law", Maine Law Review, 2018, Vol 70, n 2, pp. 160 a 197, p. 177.

${ }^{46}$ En esta línea, favorable a la defensa de la existencia de una definición de la residencia habitual, vid. M. A. GANDía SELLENS, "La responsabilidad parental y la sustracción de menores en la propuesta de la Comisión para modificar el RB II Bis: algunos avances, retrocesos y ausencias", AEDIPr, T. XVII, 2017, pp. 799 a 820, p. 814.

${ }^{47}$ Opina contrariamente a nosotros, afirmando que la concreción de esta definición autónoma es especialmente difícil y en nada beneficiaría al interés superior del menor, M. GuZmán PeCES, "Problemática en la coordinación de los instrumentos normativos aplicables a la sustracción de menores y en particular a la interpretación de la residencia habitual", $A E D I P r$, T. XIV-XV, 


\section{Criterios de residencia habitual de los niños y niñas}

14. Estos criterios ya han sido definidos por la Jurisprudencia del TJUE. No deben ser cuantitativos, sino cualitativos, debiendo tener muy en cuenta las condiciones generales del desarrollo personal y formativo de los niños y niñas según su edad en el momento en el que se analiza su residencia. Se debe valorar su madurez, escolarización, el tiempo y el lugar de residencia del menor durante los momentos anteriores a la aparición del conflicto que provoque la crisis entre los progenitores, los motivos y tiempos de sus traslados, y su mayor o menor relación con ambos padres o solo con uno de ellos. También se deben valorar sus lazos familiares con otras personas que no sean sus padres y su entorno social o los amigos con los que comparte su vida ${ }^{48}$ y su opinión si tiene madurez. Otros factores a valorar, pero con menor importancia, son su nacionalidad, el idioma en el que se expresa y los acuerdos anteriores que hayan existido entre los progenitores.

\section{Conclusiones}

15. La residencia habitual, principal criterio de localización de la competencia judicial internacional y punto de conexión de la ley aplicable en el derecho europeo de familia y sucesiones, sigue considerándose por el legislador europeo como un concepto fáctico que no debe ser definido, sino concretado ex casu por la Jurisprudencia de los tribunales. Cumpliendo esta labor el TJUE ha realizado un intenso y meritorio trabajo de creación de un concepto autónomo de residencia habitual de los niños y las niñas en el que se concretan los aspectos de hecho a valorar de la misma para que las partes, las más interesadas, y los Tribunales, la determinen. En especial en situaciones internacionales conflictivas complejas. Sin embargo, como vemos en el caso aquí estudiado, en la práctica en no pocas ocasiones esta doctrina jurisprudencial no es correctamente aplicada, provocando un evidente daño al interés más necesario de protección, el de los niños y niñas, que ven vulnerado su derecho a la tutela judicial efectiva sin dilaciones indebidas.

16. El TJUE ha concretado que para establecer la residencia habitual de los niños y niñas se debe valorar su edad y madurez, los motivos y tiempos de sus traslados, la relación con quienes ejercen la patria potestad y el resto de sus lazos familiares, su escolarización y actividades en los Estados en los que ha vivido, todo ello con mayor importancia justo antes del surgimiento de la crisis familiar. Otros factores secundarios son su nacionalidad y el idioma en el que se expresan, sin ser determinantes los anteriores acuerdos que hayan existido entre los progenitores que pueden variar en las crisis familiares internacionales. En el caso analizado el Tribunal de Instancia otorgó erróneamente mayor valor al lugar de nacimiento del menor, la anterior residencia de los padres en Suiza y la inexistencia de acuerdo entre ambos. La Audiencia Provincial ponderó correctamente la estancia en Barcelona de común acuerdo de la familia durante un tiempo significativo anterior al conflicto, la estabilidad de dicha estancia con alquiler de 3 años y escolarización del menor. La existencia de un concepto de residencia habitual en el derecho positivo europeo hubiese sido un instrumento adecuado al efecto y habría ofrecido a la juzgadora de instancia criterios más claros para evitar esta confusión y con ello el perjuicio sufrido por el menor. La refundición de Bruselas II bis demuestra, por ahora, y para nosotros por desgracia, que el legislador europeo no es de la misma opinión.

2014-2015, pp. 489 a 522, p. 519. Reig Fabado expone la inexistencia de un concepto de la residencia habitual de los niños y las niñas en el actual marco regulatorio de la sustracción internacional de menores, y sin decantarse a favor de la concreción legislativa sí destaca el intenso esfuerzo del TJUE de crear un concepto autónomo en atención al contexto de las disposiciones y los objetivos del Reglamento, siempre concretado ex casu en atención al conjunto de circunstancias de cada supuesto. Vid. I. REIG FABADO, "La construcción del concepto autónomo de residencia habitual del menor en los supuestos de sustracción internacional de menores", $C D T$, marzo 2019, Vol. 11, nº 1, pp. 877 - 888, p. 887.

${ }^{48}$ El actual Reglamento Bruselas II bis no define el concepto de menor, pero sí lo hace en su artículo 2.6 su refundición, aplicable a partir del 1 de agosto de 2022, fijándolo en todo menor de 18 años, por lo que los Tribunales podrán deber analizar situaciones de adolescentes, por ejemplo, con circunstancias e intereses absolutamente diversos al niño de nuestro caso, por ejemplo. 